\title{
Dalton Communications
}

\section{Synthesis, Photophysical Properties and Crystal Structure of a Luminescent Binuclear Three-co-ordinated Gold(1) Complex without Metal-Metal Interaction}

\author{
Shen-Jye Shieh, ${ }^{a}$ Dan Li, ${ }^{b}$ Shie-Ming Peng ${ }^{*, a}$ and Chi-Ming Che ${ }^{*, b}$ \\ a Department of Chemistry, National Taiwan University, Taipei, Taiwan, Republic of China \\ ${ }^{b}$ Department of Chemistry. The University of Hong Kong, Pokfulam Road, Hong Kong
}

\begin{abstract}
The complex cation $\left[\mathrm{Au}_{2} \mathrm{~L}_{3}\right]^{2+}[\mathrm{L}=2,6$-bis(diphenylphosphino)pyridine $]$ has an intramolecular Au $\ldots \mathrm{Au}$ separation of $4.866 \AA$ as determined by $X$-ray crystallography and displayed photoluminescence at $520 \mathrm{~nm}$
\end{abstract} in fluid solutions at room temperature.

There has been a recent interest in polynuclear gold(I) complexes with bridging phosphine ligands, because of the intriguing photophysical and photochemical properties of this class of complexes. ${ }^{1-3}$ Those polymetallic gold(I) phosphine complexes which exhibit room-temperature photoluminescence have been shown by X-ray crystallography to have intramolecular $\mathrm{Au} \cdot . \mathrm{Au}$ separations around $2.9-3.2 \AA$, suggesting weak metal-metal interaction in these complexes. It has been suggested that the photoluminescence of polynuclear metal $\mathrm{d}^{10}$ complexes arises from metal-centred $n \mathrm{~d}^{9}(n+1) \mathrm{s}^{1}$ electronic excited states which are modified by metal-metal interaction. ${ }^{4}$ Herein is described a binuclear three-co-ordinated gold(I) complex which exhibits room-temperature photoluminescence in the absence of a Au-Au interaction. Furthermore, this species can also be viewed as a luminescent inorganic host, an area of research recently investigated by Balch et al. ${ }^{5}$

The ligand 2,6-bis(diphenylphosphino)pyridine $\mathrm{L}$ was prepared by a literature method. ${ }^{6}$ Reaction between $\mathrm{KAuCl}_{4}(0.2$ g) and 2,2'-thiodiethanol $\left(1 \mathrm{~cm}^{3}\right)$ in hot methanol $\left(30 \mathrm{~cm}^{3}\right)$ for 15 min gave a colourless solution of $\mathrm{Au}^{\mathrm{I}}$ in situ, which rapidly reacted with excess $\mathrm{L}(0.3 \mathrm{~g})$ to give the colourless perchlorate salt $\left[\mathrm{Au}_{2} \mathrm{~L}_{3}\right]^{2+}$. Addition of $\mathrm{LiClO}_{4}(1 \mathrm{~g})$ to the solution gave $\left[\mathrm{Au}_{2} \mathrm{~L}_{3}\right]\left[\mathrm{ClO}_{4}\right]_{2}$ (yield $\approx 70 \%$ ). Recrystallization of the crude sample by diffusion of diethyl ether into acetonitrile solution gave colourless crystals from which the structure has been determined by X-ray crystallography. $\dagger$ Fig. 1 shows a per-

† Crystal data: $\mathrm{C}_{87} \mathrm{H}_{69} \mathrm{Au}_{2} \mathrm{Cl}_{2} \mathrm{~N}_{3} \mathrm{O}_{8} \mathrm{P}_{6} \cdot 1.5 \mathrm{C}_{4} \mathrm{H}_{10} \mathrm{O}, M_{\mathrm{r}}=2046.63$, triclinic, space group $P \overline{1}, a=14.823(6), b=18.307(6), c=18.855(12)$ $\AA, \alpha=76.02(4), \beta=84.23(4), \gamma=66.71(3)^{\circ}, U=4560(4) \AA^{3}, Z=2$, $D_{\mathrm{c}}=1.491 \mathrm{~g} \mathrm{~cm}^{-3}$, crystal dimensions $=0.20 \times 0.20 \times 0.20 \mathrm{~mm}$, $\mu=5.00 \mathrm{~mm}^{-1}, F(000)=2042$, no. of parameters $(p) 974$, no. of unique reflections $(n) 11880$, no. of reflections with $I>2 \sigma(I) 7348, R^{\prime}[=\Sigma$ $\left.\left.\left|F_{0}-F_{\mathrm{c}}\right| / \Sigma\left|F_{\mathrm{o}}\right|\right]=0.040 ; \quad R^{\prime}\left\{=\Sigma w\left(\left|F_{\mathrm{o}}\right|-\mid F_{\mathrm{c}}\right)^{2} / \Sigma w\left(\mid F_{\mathrm{o}}\right)^{2}\right]^{\frac{1}{2}}\right\}=0.039$, goodness of fit $\left\{=\left[\sum w\left(\left|F_{\mathrm{o}}\right|-\left|F_{\mathrm{c}}\right|\right)^{2} /(n-p)\right]^{\frac{1}{2}}\right\}=1.94$; weighting scheme $w=1 / \sigma^{2}\left(F_{0}\right)$. Raw intensities collected on a Nonius CAD4 fully automated four-circle diffractometer (graphite-monochromatized Mo-K $\alpha$ radiation) using the $\omega-2 \theta$ scan mode. All data reduction and structure refinement were performed using the NRCC-SDP-VAX packages available from S.-M. Peng upon request. The structure was solved by the Patterson method and refined by least-squares analysis. Atomic coordinates, bond lengths and angles, and thermal parameters have been deposited at the Cambridge Crystallographic Data Centre. See Instructions for Authors, J. Chem. Soc., Dalton Trans., 1993, Issue 1, pp. xxiii-xxviii. spective view of the complex cation with atom numbering. The structure resembles that of $\left[\mathrm{Au}_{2}\left(\mathrm{Me}_{2} \mathrm{PCH}_{2} \mathrm{CH}_{2} \mathrm{PMe}_{2}\right)_{3}\right]^{2+7}$ and $\left[\mathrm{Au}\left(\mathrm{PPh}_{3}\right)_{3}\right]^{+8}$ in that the co-ordination around each gold atom is essentially trigonal planar with $\mathrm{P}-\mathrm{Au}-\mathrm{P}$ angles ranging from $115.8(1)$ to $122.1(1)^{\circ}$. The measured intramolecular $\mathrm{Au} \cdot \mathrm{AAu}$ separation of $4.866 \AA$ suggests no metal-metal interaction in this complex.

Unlike $\left[\mathrm{Au}_{2}(\mathrm{dppm})_{2}\right]^{2+}[\mathrm{dppm}=$ bis(diphenylphosphino)methane] which shows an intense $d_{\sigma^{*}} \longrightarrow p_{\sigma}$ transition at 290 $\mathrm{nm},{ }^{1 a, 2}$ the absorption spectrum of $\left[\mathrm{Au}_{2} \mathrm{~L}_{3}\right]^{2+}$ in acetonitrile is dominated by a broad absorption band tailing from 250 to 360 $\mathrm{nm}\left(\varepsilon_{\max }=8.03 \times 10^{4} \mathrm{dm}^{3} \mathrm{~mol}^{-1} \mathrm{~cm}^{-1}\right.$ at $260 \mathrm{~nm}, 3.12 \times 10^{4}$ $\mathrm{dm}^{3} \mathrm{~mol}^{-1} \mathrm{~cm}^{-1}$ at $300 \mathrm{~nm}$ ). For a three-co-ordinated gold(I) phosphine complex, the highest occupied molecular orbital (HOMO) is $\left(5 \mathrm{~d}_{x y}, 5 \mathrm{~d}_{x^{2}-y^{2}}\right)$ whereas the lowest unoccupied molecular orbital (LUMO) is $6 \mathrm{p}_{z}$ mixed with the $\pi^{*}$ orbital of L. ${ }^{9}$ Thus we assign tentatively the low-energy absorptions at $300-360 \mathrm{~nm}$ to arise from $\left(5 \mathrm{~d}_{x^{2}-y^{2}}, 5 \mathrm{~d}_{x y}\right) \longrightarrow\left(6 \mathrm{p}_{e}, \pi^{*}\right)$ transitions. ${ }^{10}$ Similar spectral assignments have also been suggested by Fackler and co-workers ${ }^{10 a}$ and Gray and coworkers ${ }^{10 b}$ on related gold(I) phosphine complexes. Although no metal-metal interaction is anticipated in this complex, it does show photoluminescence both in the solid state and in degassed acetonitrile. Fig. 2 shows the excitation and emission spectra measured in degassed acetonitrile at room temperature. Upon excitation at $300-360 \mathrm{~nm}$, two emissions centred at 415 and $520 \mathrm{~nm}$ with lifetime of 0.3 and $1.8 \mu$ s respectively are observed. The lower energy emission with a quantum yield of 0.0018 is much more intense than the higher energy one. We assign the $415 \mathrm{~nm}$ emission to arise from the intraligand excited state since the free ligand $\mathrm{L}$ also shows weak emission at similar energy. The low-energy emission is likely to arise from the spinforbidden $\left(6 \mathrm{p}_{z}, \pi^{*}\right) \longrightarrow\left(5 \mathrm{~d}_{x^{2}-y^{2}}, 5 \mathrm{~d}_{x y}\right)$ transition ${ }^{10}$ or a metalperturbed intraligand ${ }^{3}\left(\pi, \pi^{*}\right) \longrightarrow\left(\pi^{2}\right)$ transition. The fact that the present complex has similar emission energy as that for $\left[\mathrm{Au}_{2}(\mathrm{dppm})_{2}\right]^{2+}$ (emission at $\left.570 \mathrm{~nm}\right)^{1 a, 2}$ argues against the $\left[d_{\sigma^{*}} p_{\sigma}\right]$ triplet excited state to be responsible for the photoluminescence of polymetallic gold(I) phosphine complexes. ${ }^{10}$

Similar to its $\left[\mathrm{Rh}_{2} \mathrm{~L}_{2}(\mathrm{CO})_{2} \mathrm{Cl}_{2}\right]$ analogue which has been found to bind to $\mathrm{SnCl}_{2},{ }^{11}$ the $\left[\mathrm{Au}_{2} \mathrm{~L}_{3}\right]^{2+}$ complex cation can also be viewed as an inorganic host having a cavity size of about 4.8-5.0 $\AA$ in diameter. The pyridyl functional group should facilitate binding reactions with metal ions and the photo- 


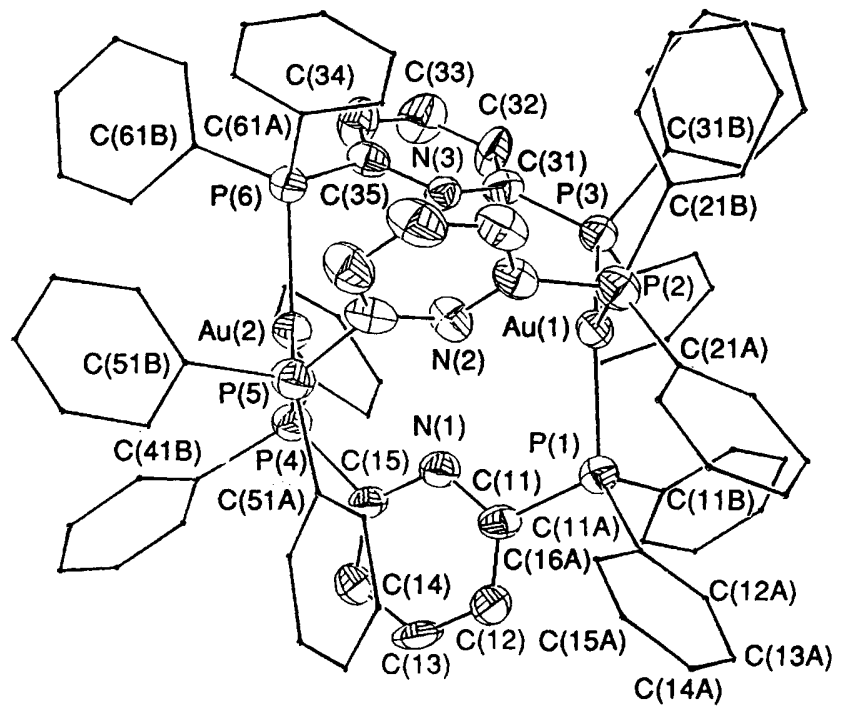

Fig. 1 A perspective view of the $\left[\mathrm{Au}_{2} \mathrm{~L}_{3}\right]^{2+}$ cation with atom numbering. Selected bond distances $(\AA)$ and angles $\left({ }^{\circ}\right)$ : $\mathrm{Au}(1)-\mathrm{P}(1)$ 2.384(4), Au(1)-P(2) 2.362(4), Au(1)-P(3) 2.357(4), Au(2)-P(4) 2.338(4), $\mathrm{Au}(2)-\mathrm{P}(5)$ 2.355(4), $\mathrm{Au}(2)-\mathrm{P}(6)$ 2.366(4), P(1)-Au(1)-P(2) 118.6(1), $\mathbf{P}(1)-\mathrm{Au}(1)-\mathbf{P}(3)$ 118.1(1), $\mathrm{P}(2)-\mathrm{Au}(1)-\mathrm{P}(3)$ 122.0(1), $\mathrm{P}(4)-\mathrm{Au}(2)-\mathrm{P}(5)$ 122.1(1), $\mathrm{P}(4)-\mathrm{Au}(2)-\mathrm{P}(6)$ 122.1(1), P(5)-Au(2)-P(6) 115.8(1)

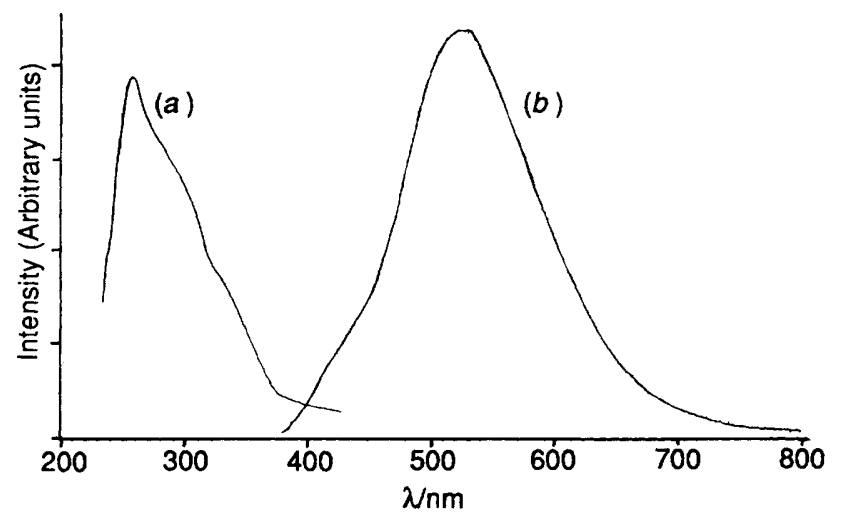

Fig. 2 Excitation $(a)$ and emission $(b)$ spectra of $\left[\mathrm{Au}_{2} \mathrm{~L}_{3}\right]^{2+}\left(\approx 10^{-5}\right.$ mol dm$~^{-3}$ ) measured in degassed acetonitrile at room temperature

luminescence can serve as a spectroscopic probe for such binding reactions. Preliminary studies revealed that the presence of $\mathrm{Li}^{+}$ion in acetonitrile does not affect the luminescence. However, in the presence of $\mathrm{CF}_{3} \mathrm{CO}_{2} \mathrm{H}$, $\mathrm{AgCF}_{3} \mathrm{SO}_{3}$ or $\left[\mathrm{Cu}(\mathrm{MeCN})_{4}\right] \mathrm{PF}_{6}$, the emission spectrum is significantly perturbed, as illustrated in Fig. 3. Trifluoroacetic acid appears to quench the emission. The substantial enhancement of the emission intensity and the red-shift in its energy in the presence of $\mathrm{Cu}^{\mathrm{l}}$ (see Fig. 3) suggests that $\left[\mathrm{Au}_{2} \mathrm{~L}_{3}\right]^{2+}$ can be used as a sensor for this cation.

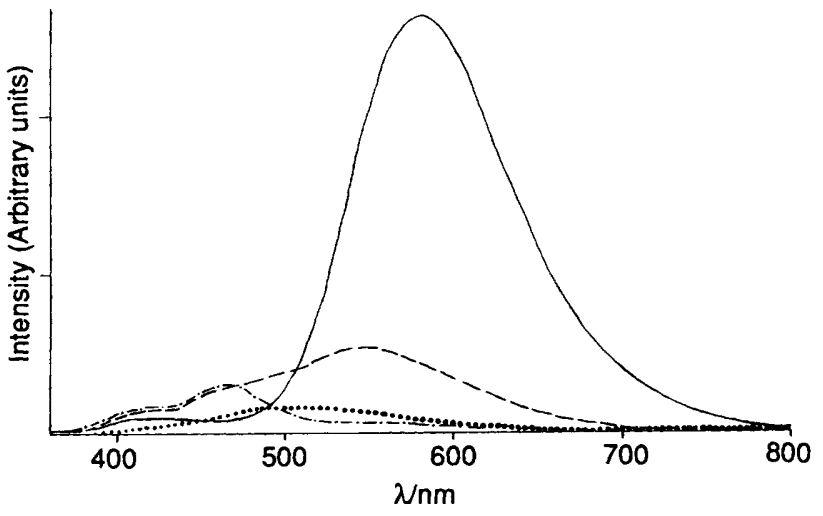

Fig. 3 Emission spectra of $\left[\mathrm{Au}_{2} \mathrm{~L}_{3}\right]^{2+}\left(1 \times 10^{-4} \mathrm{~mol} \mathrm{dm}^{-3}\right)$ in degassed acetonitrile $(\cdots)$ and in the presence of $\mathrm{CF}_{3} \mathrm{CO}_{2} \mathrm{H}\left(1 \times 10^{-3}\right.$ $\mathrm{mol} \mathrm{dm}{ }^{-3}, \ldots \cdot \ldots, \mathrm{AgCF}_{3} \mathrm{SO}_{3}\left(1 \times 10^{-3} \mathrm{~mol} \mathrm{dm}^{-3}, \ldots\right)$ or $\left[\mathrm{Cu}(\mathrm{MeCN})_{4}\right] \mathrm{PF}_{6}\left(1 \times 10^{-3} \mathrm{~mol} \mathrm{dm}^{-3}, \longrightarrow\right)$

\section{Acknowledgements}

We acknowledge support from the National Science Council of Taiwan and the Hong Kong Research Grant Council. C.-M. C. and D. L. acknowledge the receipt of a visiting Professorship and a scholarship administered by the National Taiwan University and $\mathrm{Li} \mathrm{Ka}$ Shing Foundation, respectively.

\section{References}

1 (a) C.-M. Che, H.-L. Kwong, C.-K. Poon and V. W.-W. Yam, J. Chem. Soc., Dalton Trans., 1990, 3215; (b) V. W.-W. Yam, T.-F. Lai and C.-M. Che, J. Chem. Soc., Dalton Trans., 1990, 3747; (c) C.-M. Che, H.-K. Yip, V. W.-W. Yam, P.-Y. Cheung, T.-F. Lai, S.-J. Shieh and S.-M. Peng, J. Chem. Soc., Dalton Trans., 1992, 427.

2 C. King, J. C. Wang, N. I. Md. Khan and J. P. Fackler, jun., Inorg. Chem., 1989, 28, 2145.

3 A. L. Balch, E. Y. Fung and M. M. Olmstead, J. Am. Chem. Soc., $1990,112,5181$

4 A. Vogler and H. Kunkely, J. Am. Chem. Soc., 1986, 108, 7211; Chem. Phys. Lett., 1988, 150, 135; 1989, 158, 74; H. Kunkely and A. Vogler, Chem. Phys. Lett., 1989, 164, 621.

5 A. L. Balch, J. K. Nagle, M. M. Olmstead and P. E. Reedy, jun., J. Am. Chem. Soc., 1987, 109, 4123; A. L. Balch, M. M. Olmstead, D. E. Oram, P. E. Reedy, jun., and S. H. Reimer, J. Am. Chem. Soc., 1989, 111, 4021; A. L. Balch, V. J. Catalano, B. C. Noll and M. M. Olmstead, J. Am. Chem. Soc., 1990, 112, 7558; A. Sykes and K. R. Mann, J. Am. Chem. Soc., 1988, 110, 8252.

6 G. R. Newkome and D. C. Hagen, J. Org. Chem., 1978, 43, 947

7 W. Bensch, M. Prelati and W. Ludwig, J. Chem. Soc., Chem. Commun., 1986, 1762.

8 P. G. Jones, J. Chem. Soc., Chem. Commun., 1980, 1031; Acta Crystallogr., Sect. B, 1980, 36, 3105.

9 H.-R. C. Jaw, M. M. Savas and W. R. Mason, Inorg. Chem., 1989, 28 , 4366.

10 (a) C. King, M. N. I. Khan, R. J. Staples and J. P. Fackler, Inorg. Chem., 1992, 31, 3236; (b) T. M. McClesky and H. B. Gray, Inorg. Chem., 1992, 31, 1733.

11 A. L. Balch, H. Hope and F. E. Wood, J. Am. Chem. Soc., 1985, 107, 6936.

Received 21st September; Communication 2/05036F 